\title{
Недостатки в системе глобального управления и их последствия для образования в сфере обороны
}

\author{
Фред Таннер
}

Те, кто вносит свой вклад в дело международного мира и стабильности, работают в постоянно меняющейся, все более сложной и взаимосвязанной глобальной среде. Международный ландшафт безопасности существенно изменился за последние двадцать лет, произошли важные сдвиги в распределении сил в международных делах, ускорилась динамика глобализации, стали доступными современные информационные технологии, произошла диверсификация сильных акторов в мировой политике. Кроме того, множество транснациональных вызовов безопасности - варьирующих от распространения оружия до организованной преступности, в том числе и торговля людьми, влияние миграции на безопасность и вызовы информационной и кибербезопасности - стоят на повестке дня.

Глобальное управление, понимаемое здесь как совместные механизмы взаимодействия между разными международными акторами - государствами, международными и региональными организациями, а так же акторами из частного сектора и гражданского общества, - установленные для управления глобальными процессами в условиях глобализации и при отсутствии мирового правительства, пока еще является слабым, когда речь идет об адаптации к этим изменениям. Сегодня имеются существенные недостатки в глобальном управлении, касающиеся проблем мира и международной безопасности, и вероятно, они будут существовать и в будущем. Ключевым следствием этого является постоянное присутствие нестабильности и беспорядка. В таких ситуациях неопределенности существует потребность в руководстве и в тесном сотрудничестве между партнерами. Образование будет иметь решающее значение для того, чтобы вооруженные силы в этой среде были в состоянии выполнять свою роль. Поэтому лидерские умения, политическая информированность и универсальность будут важными элементами образования в сфере обороны.

Недостаток глобального управления требует от нас лучшего понимания и более адекватной реакции на изменения в ландшафте международной безопасности, в том числе и на изменения в моделях вооруженных конфликтов и других форм насилия, на нарастание угроз финансовой и экономической безопасности, на развитие и распространение новых технологий. Все эти факторы и определяют наше мышление в сфере обороны и безопасности.

П Посол Фред Таннер является директором Женевского Центра политики безопасности, ЖЦПБ. Эта статья представляет собой отредактированную версию ведущей речи, произнесенной на 41 конференции начальников Колледжа обороны НАТО в Париже 20-22 мая 2012 года. Автор выражает свою благодарность научному сотруднику Александре Род за ценную помощь при подготовке этой статьи. 


\section{Изменяющийся ландшафт безопасности}

Международная система стала свидетелем драматических изменений, происходящих в течение последних двадцати лет, сдвигов, которые оказывают влияние на национальную, региональную и международную политику безопасности. Период Холодной войны был периодом стабильности, но также и потенциально апокалипсическим периодом соперничества ядерных суперсил. После распада Советского Союза Соединенные Штаты остались единственной сверхдержавой и доминирующей международной системой, содействующей либерализму во всем мире. В период после окончания холодной войны международные и региональные организации окрепли, став влиятельными участниками в международных делах. Организация Объединенных Наций приобретала все большее значение на мировой арене, и НАТО, и ЕС также расширили сферу своей деятельности, включив в нее менеджмент кризисов и стабилизационные миссии. Они изменили политическую и стратегическую карту Европы, расширяясь на восток, приняв бывших членов Варшавского договора и некоторые бывшие республики Советского Союза.

Начало нового тысячелетия было отмечено нападениями 11 сентября 2001 года и развертыванием глобальной войны против терроризма. В последующие годы асимметричная война и возврат к применению силы и интервенционализм сформировали международную политику безопасности. В то же время мир стал свидетелем медленного, но постоянного восхода новых могучих государств-акторов, таких как Бразилия, Россия, Индия и Китай (получивших коллективное наименование БРИК), и перераспределения глобальной мощи от Атлантического к Тихому океану. В частности, приобрел значительную мощь Китай, превращаясь во вторую по величине экономику в мире после США.

В дополнение к этим «тектоническим» изменениям, на сегодняшний ландшафт безопасности в последнее время очень сильное влияние оказывают два фактора: глобальный экономический и финансовый кризис от 2008 года и начало национальных движений в Северной Африке и на Ближнем Востоке, объединенных под наименованием «Арабская весна» или «Арабское пробуждение». Экономический и финансовый кризис оказал существенное влияние на национальные, региональные и международные мир и стабильность. Что касается трудных переходов в арабском мире, положительные признаки в свою очередь затенены вооруженным насилием, исламистским радикализмом и гражданской войной.

\section{“Attention, un train peut en cacher un autre”(«Будьте осторожны, один поезд может скрыть приближение другого»)}

Кроме этих основных событий в мировой политике, и разные другие тенденции оказали влияние и все еще продолжают формировать международную среду безопасности и глобальное управление. ${ }^{1}$ Сегодня мир сталкивается с последовательно-

1 Смотри: Fred Tanner, Nayef R.F. Al-Rodhan, and Sunjay Chandiramani, "Security Strategies Today: Trends and Perspectives," GCSP Geneva Paper 9 (April 2009). 
стью транснациональных угроз безопасности, которые не были известны двадцать лет назад, угроз, которые развились в условиях глобализации. ${ }^{2}$ Распространение организованной преступности (включая торговлю людьми), распространение оружия массового уничтожения (в частности ядерного оружия и систем его доставки), крайняя бедность, гуманитарные кризисы и распространение болезней, - и это только часть наиболее спешных, подлежащих решению проблем - имеют глобальное измерение, переходят национальные границы и требуют общей реакции.

Кроме того, множество последствий для сегодняшней безопасности имеет массовое распространение современных информационных и коммуникационных технологий. Такие платформы социальных медиа как Фейсбук, Ютуб, Твиттер сыграли ключевую роль в ходе арабских революций. ${ }^{3}$ Крупные военно-технические достижения, такие, как использование беспилотных летательных аппаратов, меняют способы ведения войны. А Интернет стал полем боя кибервойны и киберпреступности.

В последние годы мы также стали свидетелями изменений в понимании безопасности. Государства постепенно теряют свою монополию на безопасность, расширяется участие негосударственных акторов. Международные и региональные организации становятся ключевыми факторами, особенно в разрешении конфликтов, строительстве мира и оказании гуманитарной помощи. В этом контексте стали обращать большее внимание на связь между развитием, социальной справедливостью и безопасностью, что привело к расширению спектра связанных с безопасностью политики и действий.

Эффективное глобальное управление сталкивается также с вызовами, порожденными постоянной диверсификацией спектра сильных акторов в мировой политике, а именно с восходом таких негосударственных акторов, как неправительственные организации гражданского общества, многонациональные фирмы и общественные движения. Численность и адекватность негосударственных акторов драматически возросли за последние годы и привели к существенному сдвигу могущества между экономикой и гражданским обществом с одной стороны и государствами с другой. Увеличивающееся число таких негосударственных акторов, как преступные организации и террористические группы, порождает беспрецедентную опасность.

2 Что касается транснациональных вызовов европейской и глобальной безопасности, смотри доклад Европейского Союза «Стратегия внутренней безопасности Европейского Союза: на пути к модели европейской безопасности», обнародованный в марте 2010 года; и Стратегическую концепцию НАТО «Активное участие. Современная оборона», принятую руководителями государств и правительств на саммите НАТО в Лиссабоне 19-20 ноября 2010 года.

3 Смотри: Reda Benkirane, "The Alchemy of Revolution: The Role of Social Networks and New Media in the Arab Spring," GCSP Policy Paper 2012/7 (June 2012). 


\section{Недостатки глобального управления}

Международная система безопасности постоянно меняется, в условиях глобализации появляются неизвестные до сих пор вызовы и новые могущественные акторы. Глобальное управление должно адаптироваться к этим переменам с тем, чтобы идти в ногу с развитием событий. Однако, существующие структуры глобального управления все еще слабы. Три примера позволяют нам проиллюстрировать, как нынешнее устройство глобального управления не может ответить на все более сложные и многоуровневые вызовы безопасности: ядерное сдерживание и использование силы, изменяющиеся модели вооруженных конфликтов и других форм насилия, как и двойственный характер современных технологий.

\section{Ядерное сдерживание и использование силь}

Несмотря на окончание Холодной войны, ядерное сдерживание все еще широко используется как инструмент политики в паневропейском регионе и в мире в целом. Ядерное сдерживание основано на явной угрозе использования ядерного оружия. Все постоянные члены Совета безопасности ООН все еще поддерживают существенные ядерные арсеналы, предназначенные для сдерживания. НАТО, к примеру, также заявляет, что останется ядерным альянсом, пока этот вид вооружений продолжает существовать. Государства-члены НАТО в очередной раз подчеркнули, что будут придерживаться этого принципа на саммите в Чикаго в мае 2012 года, заявив в «Обзоре концепции сдерживания и обороны», что Альянс будет придерживаться к «рациональному сочетанию ядерных, конвенциональных и противоракетных боевых способностей с целью выполнения своих обязанностей», и что «ядерные вооружения являются ключевым элементом целостных способностей НАТО для сдерживания и обороны». ${ }^{4}$ Эта связь ядерного сдерживания в Европе с существованием ядерного оружия во всем мире не способствует идеалу «единой, свободной и мирной Европы». Кроме того, опора на ядерное сдерживание поощряет и узаконивает распространение этого вида оружия. На данном этапе можно утверждать, что если сдерживание все еще является необходимым ингредиентом международной системы, то лучше его осуществлять конвенциональными средствами, потому что потенциальная цена ядерного сдерживания слишком высока.

Существует более двух тысяч субстратегических ядерных зарядов, расположенных на европейской земле как части внутриевропейской структуры сдерживания. ${ }^{5}$ Продолжающееся присутствие субстратегических ядерных оружий должно

4 NATO, "Deterrence and Defense Posture Review," issued on 20 May 2012 at the 2012 NATO Summit in Chicago; доступно на: www.nato.int/cps/en/natolive/official_texts_87597.htm? mode $=$ pressrelease.

5 В 2010 году, Объединенное королевство и Франция имели вместе 525 стратегических ядерных зарядов. Смотри Robert S. Norris and Hans M. Kristensen, "Global Nuclear Weapons Inventories, 1945-2010," Bulletin of the Atomic Scientists 66 (2010): 77-83. K 2010 году, США имели 150-200 стратегических ядерных зарядов, расположенных в Бельгии, Германии, Италии, Нидерландах и Турции. Смотри Robert S. Norris and Hans M. Kris- 
заботить нас всех. Эти вооружения более не служат никаким легитимным стратегическим целям. Их существование продолжает представлять опасность для общества Европы, хотя их число существенно сократилось по сравнению с периодом Холодной войны. Всегда есть остаточный риск ядерного инцидента, кражи ядерного оружия и ядерного терроризма. Уничтожение субстратегических ядерных оружий могло бы означать возможность задействовать многосторонний процесс контроля вооружений, который занимался бы и противоракетной обороной и конвенциональными вооружениями. Подтверждение необходимости многостороннего контроля вооружений в Европе было бы важным и из-за прискорбного тупика, в который зашел Договор об обычных вооруженных силах в Европе.

Сдерживание и использование силы являются двумя сторонами одной и той же медали. В некоторых частях света продолжается использование силы. Определяющим фактором здесь является легитимность использования. К примеру, применение НАТО силы в Ливии в рамках операции «Объединенный защитник» (ОО3) с марта по ноябрь 2011 года было частью выполнения резолюции Совета Безопасности Объединенных Наций 1973 (2011), которая призывала к «незамедлительному прекращению огня» и уполномочивала международное сообщество наложить оружейное эмбарго, обеспечить запретную для полетов зону и защитить гражданские лица. Но есть случаи применения вооруженного насилия без разрешения и без санкции Объединенных Наций. В том числе и «целевые убийства», совершаемые путем односторонней интервенции и посредством ударов беспилотных летательных аппаратов. С одной стороны, продолжение такого вида насилия отражает неспособность институций глобального управления обеспечить применение международных норм, запрещающих использование силы, и исключения из этих норм, в соответствии с Уставом ООН. С другой стороны, оно иллюстрирует факт, что в сегодняшней глобальной системе меняется дефиниция использования силы.

\section{Изменение моделей вооруженных конфликтов и других форм насилия}

Несмотря на отсутствие эффективных структур глобального управления, предназначенных для решения вопросов, связанных с вооруженными конфликтами и другими формами насилия, которые существенно облегчали бы человеческое страдание, значительный прогресс во всем мире был достигнут в менеджменте кризисов и разрешении конфликтов. К сожалению, последовавшее уменьшение частоты вооруженных конфликтов с участием военных сопровождалось ростом вооруженного насилия вне традиционных областей конфликтов с участием негосударственных акторов. Доклад о состоянии безопасности человечества «Дело мира и уменьшение цены войны» весьма убедительно показывает существенное

tensen, "U.S. Tactical Nuclear Weapons in Europe, 2011," Bulletin of the Atomic Scientists 67 (2011): 64-73. 
сокращение числа вооруженных конфликтов за последние двадцать лет. ${ }^{6}$ Согласно этому докладу, после окончания Холодной войны число вооруженных конфликтов, в которых хотя бы одна из сторон является правительством, в 2009 году было на треть ниже, чем в пиковом 1992 году. Положительным является так же то, что число погибших в результате вооруженных конфликтов существенно уменьшилось за последние двадцать лет. Среднее число жертв на один конфликт после конца Холодной войны на 76 процентов ниже, чем в период Холодной войны.

Однако, остающиеся формы конфликтов и насилия не вписываются в традиционные модели войны и мира, криминального, или политического насилия. «Женевская декларация о вооруженном насилии и развитии», инициатива, которая занимается связями между вооруженным насилием и развитием, показала как отличия между политическими и криминальными видами насилия стираются в нынешней среде безопасности. ${ }^{7}$ Сегодня главное препятствие установлению мира состоит в наличии высокого уровня насильственных преступлений, который угрожает мирному процессу, общественному и экономическому развитию. ${ }^{8}$ В целом, в результате вооруженного насилия за период с 2004 по 2009 год погибали около 526000 человек в год, в том числе 55000 в ходе вооруженных конфликтов. Следовательно, около 90 процентов жертв целенаправленного вооруженного насилия погибают не в результате вооруженного конфликта, а в не-конфликтной среде изза убийств и применения правоохранительных мер. Вооруженное насилие является четвертой по значению причиной смерти людей в возрасте от 15 до 44 лет по всему миру. Один из самых удручающих примеров - это, конечно, Мексика, где связанная с наркотиками преступность сопровождается высоким уровнем насилия, приведшим к смерти 34000 человек за четырехлетний период с 2007 по 2010 год с начала наступления президента Фелипе Калдерон на наркокартели. 9 Это означает, что за тот же период больше людей было убито в Мексике, чем в Афганистане.

Изменению схем вооруженного насилия способствует изобилие и наличие легкого стрелкового оружия. Действительно, причиной приблизительно 70 процентов всех насильственных смертей является огнестрельное оружие. В Европе эта доля составляет 19 процентов, в Центральной Америке - 77 процентов. Сильно увеличилась доступность оружия для гражданского населения. Основной причиной является контрабанда и незаконная торговля огнестрельным оружием, но так же и появление зон без государственного управления и обеспечения безопасности.

6 Human Security Report Project "Human Security Report 2009/2010," доступно на: www.hsrgroup.org/human-security-reports/20092010/text.aspx.

7 Более подробную информацию можно найти на сайте инициативы www.genevadeclaration.org.

8 Смотри: Geneva Declaration Secretariat, Global Burden of Armed Violence 2011 (Cambridge: Cambridge University Press, 2011).

9 Смотри: Mark Stevenson, "Mexico: 34,612 Drug War Deaths; 15,273 in 2010," Huffington Post (12 January 2011), доступно на: http://www.huffingtonpost.com/2011/01/12/mexicodrug-war-deaths-2010_n_808277.html. 
На конференции, где рассматривался «План действий ОБСЕ по стрелковому и легкому оружию» в мае 2012 года, генеральный секретарь ОБСЕ Ламберто Заньер также подчеркнул связь между борьбой с распространением стрелкового оружия и борьбой против насильственной и организованной преступности, и указал, что ОБСЕ «должна и дальше укреплять практические связи между борьбой с незаконным стрелковым и легким вооружением и другими областями работы ОБСЕ, такими как цикл конфликта и транснациональные угрозы». ${ }^{10}$ Основным ответом на эти вызовы, по рекомендации Всемирного банка, должны быть усилия по созданию законных институтов, которые смогут обеспечить гражданам безопасность, справедливость и занятость. Речь также идет о создании структур управления безопасностью, которые являются устойчивыми и будут в состоянии надежно поддерживать правопорядок.

\section{Двойственный характер современных технологий}

Глобализация также приводит к увеличению риска и росту угроз из-за растущего двойного применения современных технологий. Мы живем во все более дигитализированном мире, с широким спектром различных информационных и коммуникационных технологий и очень динамичным технологическим сектором, который влияет на частную, государственную, экономическую и военную сферу общества. Будущие войны будут отличаться использованием существенных технологических нововведений с расширенным применением в бою машин и роботов. Даже сейчас применение роботов для разминирования дорог обсуждалось на саммите НАТО в Чикаго в мае 2012 года в качестве части инициативы «Умная оборона».

На сегодняшний день вооруженные силы и оборонные организации относятся к кибербезопасности не только как к техническому вопросу, но и как к проблеме, которая заняла прочное место в военном доктринальном мышлении. Кибербезопасность оказывает влияние на вопросы защиты и нападения на стратегическом, оперативном и тактическом уровне. Для сектора обороны взаимодействие и сотрудничество с коммерческими киберсетями имеют существенное значение. В связи с этим направлением доклад Института по изучению проблем безопасности Европейского Союза (ЕСИИБ) «Глобальные тенденции 2030: граждане взаимосвязанного и полицентрического мира» предсказывает восход новых, конкурентных и динамических киберспособностей для нападения и защиты, которые будут иметь существенное значение для экономического и военного развития, но которые тоже приведут к появлению новых зон уязвимости. ${ }^{11}$ Кибербезопасность так же заботит

10 Организация по безопасности и сотрудничеству в Европе, «Встреча ОБСЕ для пересмотра плана действий по стрелковым и легким оружиям и экспертная сессия ОБСЕ по запасам, уменьшению и уничтожению излишков стрелкового и легкого оружия: сводный доклад», 4 июля 2012 года; доступно на: www.osce.org/fsc/92811.

11 European Union Institute for Security Studies, European Strategy and Policy Analysis System Report, "Global Trends 2030: Citizens in an Interconnected and Polycentric World," 27 April 2012; доступно на: www.iss.europa.eu/publications/detail/article/espas-report-global-trends2030-citizens-in-an-interconnected-and-polycentric-world/. 
НАТО, особенно то, что касается увеличивающегося числа кибератак на правительственные администрации, бизнес, транспортные сети и сети поставок. ${ }^{12}$ Для того, чтобы решать эти проблемы, в Таллинне был создан Совместный центр HАТО для повышения квалификации по кибербезопасности (NATO CCD COE) в качестве института для исследований и подготовки кадров. Женевский центр политики безопасности поддержал этот институт своим партнерством в подготовке «Таллиннского справочника по международному законодательству, касающемуся кибервойн». 13

\section{Последствия для образования в сфере обороны}

\section{Роль вооруженных сил в турбулентном мире}

В последние годы оценка результатов деятельности вооруженных сил неоднозначна. Наиболее очевидным является вывод, что самостоятельно вооруженные силы не могут справиться с менеджментом конфликтов. Военные действия были заменены экспедиционными и стабилизационными миссиями, интервенцией и «жесткими действиями» по восстановлению и строительству государства. Что касается Афганистана, тяжелая работа, которая была сделана, и значительный прогресс, который был достигнут, к сожалению, по большей части игнорируются в сегодняшней политической дискуссии по выводу войск из страны. Более того, несмотря на успех воздушной кампании НАТО, остается нерешенным вопрос о будущем Ливии. ${ }^{14} \mathrm{~K}$ тому же, продолжающийся переход в Ливии все еще сопровождается нестабильностью как в самой стране, так и у ее соседей - в частности, исламистским восстанием в северной части Мали и террористическими акциями в Алжире, что поднимает вопрос об ответственности коалиции, особенно в отношении распространения оружия в Африке.

В постафганский период - эпоху, которая несомненно будет отмечена жесткими мерами экономии и сокращением бюджетов на оборону, - время существенного ангажирования НАТО может подойти к концу. Что касается будущих ролей и миссий Альянса, увеличивающиеся расхождения между европейскими членами НАТО подвергают Альянс внутреннему разделению. Будущее, однако, вероятнее всего потребует новых военных ангажементов в Африке, на Ближнем Востоке и в других районах за пределами евро-атлантической зоны. Партнерство и международное сотрудничество со странами в состоянии перехода в арабском мире и в Африке должны быть во главе повестки дня НАТО.

12 Смотри: NATO's Strategic Concept, “Active Engagement, Modern Defense," adopted by the heads of state and government at the NATO Summit in Lisbon, 19-20 November 2010; доступно на: www.nato.int/cps/en/natolive/official_texts_68580.htm.

13 Справочник будет опубликован в бумажном и электронном виде издательством Cambridge University Press в 2013 году.

14 Смотри: Julian Lindley-French, "Strategic Pretence or Strategic Defence? Britain, France and the Common Security and Defence Policy after Libya," GCSP Policy Paper 1 (April 2011). 
Уменьшение количества наличных ресурсов НАТО контрастирует с растущими расходами на оборону новопоявляющихся за пределами Европы сил. Действительно, будущее мира будет отмечено новой гонкой вооружения и распространением новых военных технологий. Уже сегодня четко заметен сдвиг самых больших расходов на оборону от Атлантического к Тихому океану.

\section{Проблемы проведения операций в зонах без государственного управления и обеспечиваемой государством безопасности}

Для вооруженных сил сейчас является вызовом проведение операций в драматически измененной среде в регионах, которые находятся в состоянии перехода. Районы, которые попадают в известные зоны конфликтов и в которых есть сильное присутствие вооруженных фракций, экстремистских групп и криминальных организаций, являются особенно проблематичными театрами проведения операций и поднимают множество важных вопросов. Как, к примеру, следует действовать в среде, характеризующейся асимметрией и гибридными структурами? Или как международные силы безопасности должны относиться к гибридным структурам в среде, которая нуждается в стабилизации, в которой действует теневая экономика, преступность порождает беспорядки и где применяются нетрадиционные тактики? Другой вопрос, который следует задать, это чем отличаются стабилизация и восстановление с одной стороны и контртеррористическая деятельность в том же районе, с другой. И последнее, как подготовка для действий в такой среде совмещается с подготовкой для ведения традиционных военных операций?

Руперт Смит очень хорошо иллюстрирует всю сложность современной войны в своей книге Полезность силь: Искусство войны в современном мире, которую называют трактатом о «войне между народами». ${ }^{15}$ В среде нетрадиционных конфликтов интегральный стратегический подход, совместная подготовка и совместное планирование с партнерами, с представителями международных организаций и гражданского общества, будут особенно важны. Имея в виду рост организованной преступности и размывание границ между районами с конфликтом и без конфликтов, и между политическим и криминальным насилием, подготовка в докризисной среде или среде появляющегося кризиса, как и в полуопределенной или посткризисной среде, будут одинаково важны.

\section{Модернизация подготовки и образования в сфере обороны}

Модернизация подготовки и образования в сфере обороны предоставляет важную возможность реагировать на преобладающие недостатки в глобальном управлении. Во-первых, подготовка и образование в сфере обороны требуют наведения фокуса на международные усилия. Традиционная военная подготовка проводилась на национальном уровне в национальных военных академиях. Чтобы идти в ногу с

15 Rupert Smith, The Utility of Force: The Art of War in the Modern World (New York: Penguin, 2008). 
современным развитием ситуации, необходимо, однако, чтобы военное образование делало упор на подготовку к действиям в многонациональной и многофакторной среде. С точки зрения институтов и организаций, проводящих подготовку, это означает расширение глобального охвата, к примеру, путем установления стратегических партнерств. В последние годы Женевский Центр Политики Безопасности (ЖЦПБ) создал сеть договоренностей о сотрудничестве с широким кругом образовательных организаций в сфере обороны, центрами профессиональной квалификации и университетов по всему миру. В число партнеров входят:

- Китайский Институт Международных Стратегических Исследований (КИМСИ)

- Институт исследований в сфере безопасности Южной Африки (ИИБ)

- Региональный центр в Каире по подготовке в области разрешения конфликтов и сохранения мира в Африке (ЦПРКСМА)

- Национальный университет обороны Республики Корея

- Высший королевский институт обороны министерства обороны Бельгии (ВКИО)

- Национальная академия обороны австрийских вооруженных сил.

ЖЦПБ участвует в таких совместных видах деятельности с партнерами как обмен преподавателями, совместные исследования, совместные программы подготовки и конференции. Кроме того, в сегодняшней комплексной и взаимосвязанной среде безопасности повысить качество образования в сфере обороны может развитие взаимодействия и обмена между руководителями, выходцами из различных культурных слоев в условиях совместных курсов подготовки. При общем числе участников 800 человек из 112 стран, обучающихся в 2011-2012 академическом году, при формировании персональной структуры своих курсов ЖЦПБ уделяет огромное внимание культурному разнообразию.

Во-вторых, содержание традиционных учебных программ надо актуализировать. Чтобы помочь будущим руководителям подготовиться к встрече с вызовами безопасности двадцать первого века, необходима подготовка к нетрадиционным угрозам. Эти угрозы варьируют от изменений климата до кибербезопасности и включают новые схемы реагирования (такие как электронная дипломатия) и направленность на новых акторов (таких как гражданское общество и медиа). В 2012 году ЖЦПБ организовал в сотрудничестве с партнерами несколько мероприятий с большим числом участников, посвященных проблемам международного мира и безопасности, как например, «Женевский день электронной дипломатии», семинар по кибербезопасности и публичная дискуссия на тему «Современный финансовой кризис и кризис суверенных долгов: последствия для региональной и глобальной безопасности». Эти учебные и сетевые мероприятия дали возможность специалистам обменяться мнениями по некоторым из наиболее актуальных тем в области международного мира и безопасности, что было очень хорошо воспринято в «Международной Женеве». 
В-третьих, подготовка должностных лиц в сфере обороны к многочисленным проблемам безопасности в современных условиях может потребовать более пристального внимания, обращенного на развитие соответствующих навыков. Комплексная среда требует иного подхода к управлению, включая вопросы лидерства, широту горизонта, а также культурное и политическое здравомыслие. Но и другие сопутствующие умения, такие как знание иностранного языка, коммуникационные умения, медиа-грамотность, межкультурная компетентность и информированность по гендерным вопросам также должны быть неотъемлемой частью учебных программ в сфере обороны. Комплексный подход к образованию в сфере обороны должен включать в себя набор упражнений, который предполагает и существование сети квалифицированных инструкторов и вспомогательных материалов для повышения квалификации. Учебные программы в сфере обороны также должны готовить к возможной стратегической переориентации или «смене игры» (ruptures stratégiques - разрывы стратегии), что означает, что специалисты, как ожидается, должны быть более универсальными и многофункциональными. Следует признать, что подход «один размер подходит всем» является недостаточным, чтобы противостоять различным вызовам безопасности в современной быстро меняющейся среде, и его следует избегать. 


\section{Литература}

Active Engagement, Modern Defense In NATO's Strategic Concept. Lisbon: NATO Summit, 2010.

Benkirane, Reda. "The Alchemy of Revolution: The Role of Social Networks and New Media in the Arab Spring." GCSP Policy Paper 7 (2012).

Consolidated Report. Organization for Security and Cooperation in Europe, Forum for Security Co-operation, 2012.

Deterrence and Defense Posture Review. Chicago: 2012 NATO Summit, 2012.

Global Burden of Armed Violence 2011. Cambridge: Geneva Declaration Secretariat, Cambridge University Press, 2011.

Global Trends 2030: Citizens in an Interconnected and Polycentric World. European Union Institute for Security Studies, European Strategy and Policy Analysis System Report, 2012.

Human Security Report 2009/2010. Human Security Report Project, 2010.

Internal Security Strategy for the European Union: Towards a European Security Model. European Union's report, 2010.

Lindley-French, Julian. "Strategic Pretence or Strategic Defence? Britain, France and the Common Security and Defence Policy after Libya." GCSP Policy Paper 1 (2011).

Norris, Robert S., and Hans M. Kristensen. "Global Nuclear Weapons Inventories, 1945-2010." Bulletin of the Atomic Scientists 66 (2010): 77-83.

Norris, Robert S., and Hans M. Kristensen. "U.S. Tactical Nuclear Weapons in Europe, 2011." Bulletin of the Atomic Scientists 67 (2011): 64-73.

Smith, Rupert. The Utility of Force: The Art of War in the Modern World. London: Penguin Books Ltd., 2005.

Stevenson, Mark. Mexico: 34,612 Drug War Deaths; 15,273 in 2010. Huffington Post, 2011.

Tanner, Fred, Nayef R. F. Al-Rodhan, and Sunjay Chandiramani. Security Strategies Today: Trends and Perspectives. GCSP Geneva , 2009. 